\title{
Pregabalin prescription for terminally ill cancer patients receiving specialist palliative care in an acute hospital
}

Ryo Yajima ${ }^{1,2^{*}}$, Kazuaki Matsumoto², Yuya Ise ${ }^{1}$, Norihito Suzuki ${ }^{3,4}$, Yuta Yokoyama², Junko Kizu² and Shiro Katayama ${ }^{1}$

\begin{abstract}
Background: Pregabalin is recommended as an adjuvant analgesic for neuropathic cancer-related pain, and may be taken at all steps of the World Health Organization analgesic ladder. However, unlike opioids, pregabalin treatments are limited to an oral administration route. If patients have oral feeding difficulties, it is not possible to administer any drug as an adjuvant analgesic for neuropathic cancer-related pain. Therefore, the aim of the present study was to clarify the problems of pain control after pregabalin discontinuation in terminally ill cancer patients.

Methods: Our subjects comprised cancer patients who died during their hospital stay and were referred between April 2013 and October 2015 to the palliative care team of the 899-bed Cancer Hospital at the Nippon Medical School Hospital in Japan. The medical records of each patient were retrospectively reviewed, and patient characteristics were recorded.

Results: We obtained data on 183 patients during the study period. Thirty-eight (20.8\%) patients were treated with pregabalin. Thirty-three (86.8\%) out of 38 patients were prescribed pregabalin for neuropathic cancer-related pain. The incidence of bony metastases was significantly higher in patients administered pregabalin than in those not taking the drug (non-pregabalin group $32.4 \%$ vs pregabalin group $57.9 \%$ ). Pregabalin was ultimately discontinued in all patients, with the main reason being oral feeding difficulties (81.6\%). After the discontinuation of pregabalin, the amount of opioid drugs administered was increased in $56.5 \%$ of patients with oral feeding difficulties.

Conclusion: Our results demonstrated that the amount of opioid drugs administered was increased in more than $50 \%$ of patients following the discontinuation of pregabalin, and was repeatedly increased for some patients. A new administration route is required for cancer patients unable to take oral medication.
\end{abstract}

Trial registration: UMIN000022507. May 28, 2016 retrospectively registered.

Keywords: Pregabalin, Adjuvant analgesic, Cancer pain, Terminally ill, Palliative care team

\section{Background}

Pain occurs in approximately $30 \%$ of all cancer patients, and in $60-70 \%$ and $75 \%$ of advanced and terminally ill cancer patients, respectively. Persistent pain is the most common type of pain reported in cancer patients; $50 \%$ of patients have moderate or advanced pain, while $30 \%$

\footnotetext{
* Correspondence: r-yajima@nms.ac.jp

${ }^{1}$ Section of Pharmaceutical Services, Nippon Medical School Hospital, 1-1-5 Sendagi, Bunkyo-ku, Tokyo 113-8603, Japan

${ }^{2}$ Division of Practical Pharmacy, Keio University Faculty of Pharmacy, 1-5-30

Shibakoen, Minato-ku, Tokyo 105-8512, Japan

Full list of author information is available at the end of the article
}

have advanced or unbearable pain [1, 2]. Since terminally ill cancer patients have emotional distress and physical pain, palliative care incorporates the administration of a number of different drugs including opioids, antipyretic analgesics, and adjuvant analgesics.

Cancer cells in terminally ill cancer patients spread to various sites. When metastasized cancer cells compress nerve tissue, characteristic pain, such as electric shocklike pain with tingling, develops. Pregabalin is recommended as the first-line therapy in the guidelines for neuropathic pain, is widely used as an adjuvant analgesic for patients with neuropathic pain, and may be 
taken at all steps of the World Health Organization analgesic ladder $[3,4]$.

However, unlike opioid drugs and antipyretic analgesics, pregabalin treatments are limited in Japan to an oral administration route. If terminally ill patients develop oral feeding difficulties, it is not possible to administer any drug as an adjuvant analgesic for neuropathic cancer-related pain. Therefore, pain control has not yet been established for terminally ill cancer patients with oral feeding difficulties.

The aim of the present study was to clarify the problems of pain control after pregabalin discontinuation. Therefore, we investigated the current status of pregabalin treatments in terminally ill cancer patients.

\section{Methods}

Data sources and procedures

The method used in the present study was a chart review. Subjects comprised patients with cancer who were referred between April 1, 2013 and October 31, 2015 to the palliative care team of the 899-bed Cancer Hospital at the Nippon Medical School Hospital in Japan. Inclusion criteria were: a diagnosis of incurable advanced cancer and patients who died during their hospital stay at Nippon Medical School Hospital.

\section{Demographic and patient clinical data}

Information including age, sex, the date of admission, date of death, primary cancer site, bone metastases, requested reasons for palliative care, performance status (PS) at the time of the palliative care intervention, and a prescription for pregabalin was extracted from the electronic medical records of each patient.

\section{The current status of pregabalin treatments}

Information including the prescriber, reasons for the prescription, initial dose, maintenance dose, administration period, weight, creatinine clearance $(\mathrm{Ccr})$ calculated from the Cockcroft-Gault formula, if pregabalin had been discontinued, the reason for its discontinuation, and the dose of opioid drugs before and after the discontinuation of pregabalin was extracted from the electronic medical records of patients prescribed pregabalin.

We investigated the dose of opioids administered before and after the discontinuation of pregabalin. The doses of opioid drugs were converted to morphineequivalent dose. The half-life of pregabalin according to renal function is $5-48 \mathrm{~h}$, as stated on the package insert. Therefore, based on its excretion from the body, patients who survived 4 days or more after the discontinuation of pregabalin were targeted. The initial and maintenance doses were compared to doses on the package insert. The initial dose of pregabalin (daily dose), as recommended on the package insert, in the case of Ccr $(\mathrm{mL} /$ min) $\geq 60$ was $150 \mathrm{mg}$, in the case of $60>\mathrm{Ccr} \geq 30$ was $75 \mathrm{mg}$, in the case of $30>\mathrm{Ccr} \geq 15$ was $50 \mathrm{mg}$, and in the case of $\mathrm{Ccr}<15$ was $25 \mathrm{mg}$. The maintenance dose (daily dose) and highest dose (daily dose) in each case of Ccr $\geq 60$ were $300 \mathrm{mg}$ and $600 \mathrm{mg}$, respectively, in each case of $60>\mathrm{Ccr} \geq 30$ were $150 \mathrm{mg}$ and $300 \mathrm{mg}$, respectively, in each case of $30>\mathrm{Ccr} \geq 15$ were $75 \mathrm{mg}$ and $150 \mathrm{mg}$, respectively, and in each case of $\mathrm{Ccr}<15$ were $50 \mathrm{mg}$ and $75 \mathrm{mg}$, respectively.

\section{Statistical analyses}

The Mann-Whitney U-test and chi-squared test were used to examine differences between patients prescribed and those not prescribed pregabalin. All analyses were performed with the Statistical Package for the Social Sciences (version 20.0, MAKER, LOCATION). The significance level was set at $P<0.05$.

\section{Ethical issues}

This study was approved by the Ethical Review Board of the Nippon Medical School Hospital (\#28-05-580). Patient information was coded by number, and could not be identified personally.

\section{Results \\ Background}

We obtained data on 183 patients during the study period. Thirty-eight $(20.8 \%)$ patients were being treated with pregabalin. Each patient was separated by the presence or absence of a prescription for pregabalin, and patient backgrounds are shown in Table 1 . The incidence of bony metastases was significantly higher in patients administered pregabalin than in those not taking the drug (Table 1).

\section{Prescription for pregabalin}

Twenty-five out of 38 patients were prescribed pregabalin by the Department of Palliative Care. Thirty-three out of 38 patients had been prescribed pregabalin for pain and numbness due to cancer (Table 2).

\section{Initial and maintenance doses of pregabalin}

A comparison of the initial dose of pregabalin administered to patients and the initial dose on the package insert revealed that the percentage of patients started on a smaller dose than that on the package insert in the case of $\mathrm{Ccr} \geq 60$ was $61.1 \%$, in the case of $60>\mathrm{Ccr} \geq 30$ was $69.2 \%$, in the case of $30>C c r \geq 15$ was $66.7 \%$, in the case of $\mathrm{Ccr}<15$ was $0.0 \%$, and for all cases was $62.9 \%$. The maintenance dose was compared in the same manner. The percentage of patients started on a smaller dose than that on the package insert in the case of $\mathrm{Ccr} \geq 60$ was $91.7 \%$, in the case of $60>\mathrm{Ccr} \geq 30$ was $70.0 \%$, in the case of $30>\mathrm{Ccr} \geq 15$ was $0.0 \%$, in the case 
Table 1 Patient characteristics

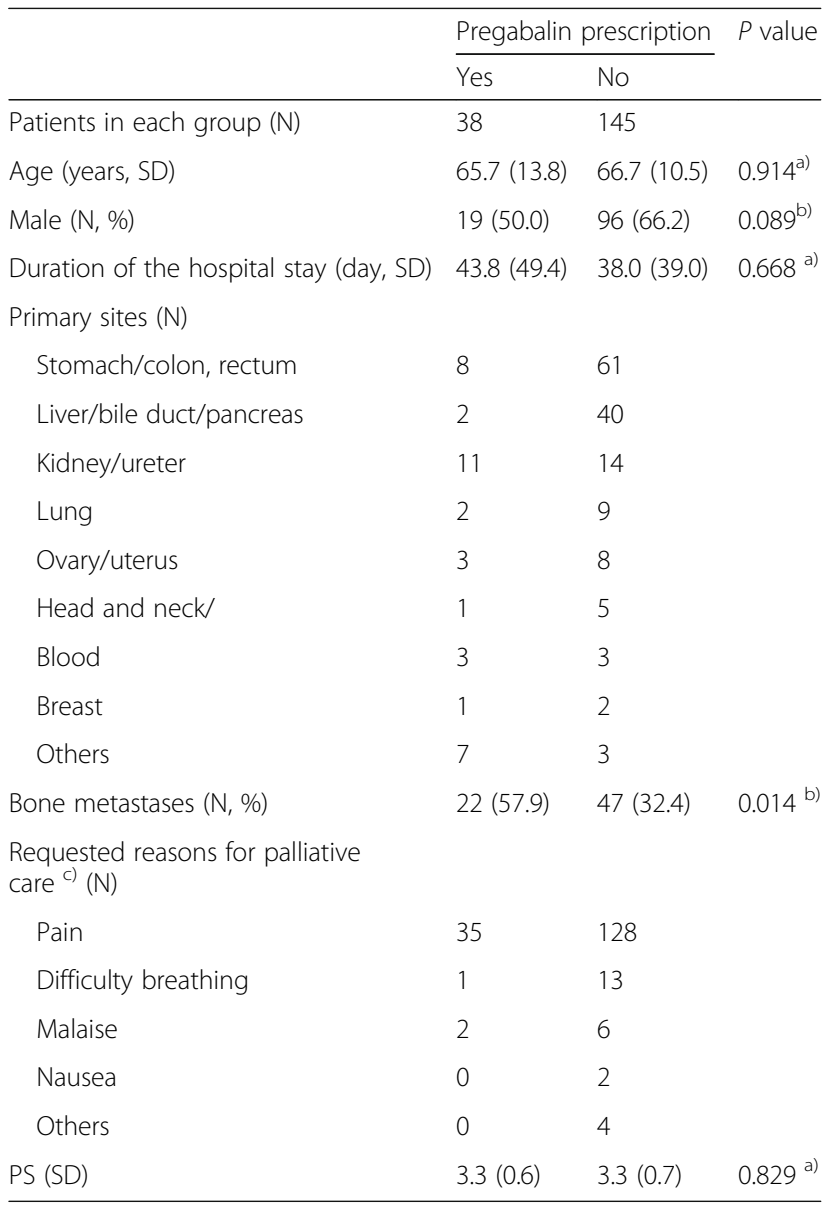

SD Standard deviation

a) Mann-Whitney U-test, ${ }^{\text {b) }}$ the chi-squared test, ${ }^{\text {c) Duplicate Yes }}$

Table 2 Pregabalin prescribers and reasons for its prescription

\begin{tabular}{ll}
\hline Diagnosis and treatment department & Number of patients $(N)$ \\
\hline Palliative care & 25 \\
Attending physicians & 8 \\
Other (orthopedics) & 3 \\
Unknown (Continuous use from & 2 \\
another hospital) & \\
Prescription reason & 33 \\
Cancer-related pain and numbness & 1 \\
Numbness due to an anti-cancer drug & 1 \\
treatment & 1 \\
Numbness due to radiation therapy & 1 \\
Numbness after shingles & 1 \\
Pain associated with fibromyalgia & \\
syndrome & Unknown
\end{tabular}

of Ccr $<15$ was $100.0 \%$, and for all cases was $72.2 \%$ (Table 3).

\section{Reasons for the discontinuation of pregabalin}

Pregabalin was ultimately discontinued in all patients, with the main reason being oral feeding difficulties $(81.6 \%)$ (Table 4$)$. Six patients discontinued pregabalin due to side effects.

The dose of opioids before and after the discontinuation of pregabalin

Pregabalin was discontinued in 31 patients due to oral feeding difficulties. Twenty-three out of 31 patients survived 4 days or more after its discontinuation. For the 3 days before the discontinuation of pregabalin, the dose of opioid drugs was increased in three patients and unchanged in 20 patients. The dose of opioid drugs administered $24 \mathrm{~h}$ after the discontinuation of pregabalin was increased in seven patients, remained unchanged in six patients, and was decreased in nine patients. Furthermore, one patient discontinued opioid drugs. This patient's medical records showed that pain was ameliorated by the effects of radiation therapy, and was controlled by an intravenous injection of NSAIDs (non-steroidal anti-inflammatory drugs).

Changes in the dose of opioid drugs administered before and after the discontinuation of pregabalin are

Table 3 The number of patients with initial dose and maintenance dose (mg/day) of pregabalin

\begin{tabular}{lllll}
\hline & \multicolumn{2}{l}{$\mathrm{Ccr}(\mathrm{mL} / \mathrm{min})$} & \\
\cline { 2 - 5 } & $\mathrm{Ccr} \geq 60$ & $60>\mathrm{Ccr} \geq 30$ & $30>\mathrm{Ccr} \geq 15$ & $\mathrm{Ccr}<15$ \\
\hline Initial dose ${ }^{\text {a) }}$ & 7 & 2 & 0 & 0 \\
$150 \mathrm{mg}$ & 5 & 2 & 1 & 0 \\
$75 \mathrm{mg}$ & 2 & 2 & 0 & 0 \\
$50 \mathrm{mg}$ & 4 & 7 & 2 & 1 \\
$25 \mathrm{mg}$ & & & & \\
Maintenance dose ${ }^{\mathrm{b})}$ & & 3 & 0 & 0 \\
$300 \mathrm{mg}$ & 1 & 0 & 0 & 0 \\
$250 \mathrm{mg}$ & 1 & 0 & 0 & 0 \\
$225 \mathrm{mg}$ & 2 & 3 & 1 & 0 \\
$150 \mathrm{mg}$ & 4 & 1 & 0 & 0 \\
$100 \mathrm{mg}$ & 0 & 4 & 2 & 0 \\
$75 \mathrm{mg}$ & 3 & 1 & 0 & 0 \\
$50 \mathrm{mg}$ & 0 & 8 & 0 & 1 \\
$25 \mathrm{mg}$ & 1 & 3 & \\
\hline
\end{tabular}

a) The initial dose ( $\mathrm{mg} /$ day) of pregabalin in the package insert, in the case of $\mathrm{Ccr}(\mathrm{mL} / \mathrm{min}) \geq 60$, was $150 \mathrm{mg}$, in the case of $60>\mathrm{Ccr} \geq 30$, was $75 \mathrm{mg}$, in the case of $30>C \mathrm{cr} \geq 15$, was $50 \mathrm{mg}$, and in the case of $\mathrm{Ccr}<15$, was $25 \mathrm{mg}$

b) The maintenance dose (mg/day) of pregabalin in the case of $\mathrm{Ccr}(\mathrm{mL} / \mathrm{min}) \geq$ 60 was $300 \mathrm{mg}$, in the case of $60>\mathrm{Ccr} \geq 30$ was $150 \mathrm{mg}$, in the case of $30>$ $\mathrm{Ccr} \geq 15$ was $75 \mathrm{mg}$, and in the case of $\mathrm{Ccr}<15$ was $50 \mathrm{mg}$ 
Table 4 Reasons for discontinuing pregabalin

\begin{tabular}{ll}
\hline Reasons for discontinuing & Number of patients $(\mathrm{N})$ \\
\hline Oral feeding difficulty & 31 \\
Adverse effect (sleepiness) & 2 \\
Adverse effect (renal dysfunction) & 2 \\
Adverse effect (diplopia) & 1 \\
Adverse effect (nausea) & 1 \\
To reduce the number of oral drugs & 1 \\
\hline
\end{tabular}

shown in Fig. 1. The dose of opioid drugs administered was higher in $12(52.1 \%)$ out of 23 patients $72 \mathrm{~h}$ after the discontinuation of pregabalin than $24 \mathrm{~h}$ after. The dose of opioid drugs was increased further in eight (66.7\%) out of 12 patients $72 \mathrm{~h}$ after the discontinuation of pregabalin. The dose of opioid drugs administered was higher in 13 (56.5\%) out of 23 patients after pregabalin was discontinued than before (Table 5).

\section{Discussion}

The results of the present study revealed that the physicians of the Department of Palliative Care mainly prescribed pregabalin to terminally ill cancer patients for pain and numbness caused by cancer (Table 2). Furthermore, the incidence of bony metastases was significantly higher in terminally ill cancer patients administered pregabalin than in those not taking the drug (Table 1), because pregabalin is effective in patients with the neuropathic pain due to bony metastases.

In the present study, the initial and maintenance doses administered were smaller than the doses described in the package insert (Table 3). Pain control was achieved without administering more than the recommended dose. The incidence of the side effects of pregabalin based on responses on an interview form was previously reported to be between 64.5 and $82.9 \%$. In the present study, the incidence of side effects was $18.8 \%$ (Table 4 ), which was very low. Previous studies reported that the incidence of side effects was higher in the elderly and patients with renal dysfunction $[5,6]$.

All patients discontinued the use of oral pregabalin (Table 4), with the main reason being oral feeding difficulties. No drugs have the same effects as pregabalin, except for oral drugs. If patients have difficulties in oral feeding, the doses of opioid drugs were adjusted (Table 5, Fig. 1). The dose of opioid drugs administered $24 \mathrm{~h}$ after the discontinuation of pregabalin was increased in seven patients due to pain exacerbation. Furthermore, doses were gradually increased over time for some patients (Fig. 1). The dose of opioid drugs administered $24 \mathrm{~h}$ after the discontinuation of pregabalin was decreased in

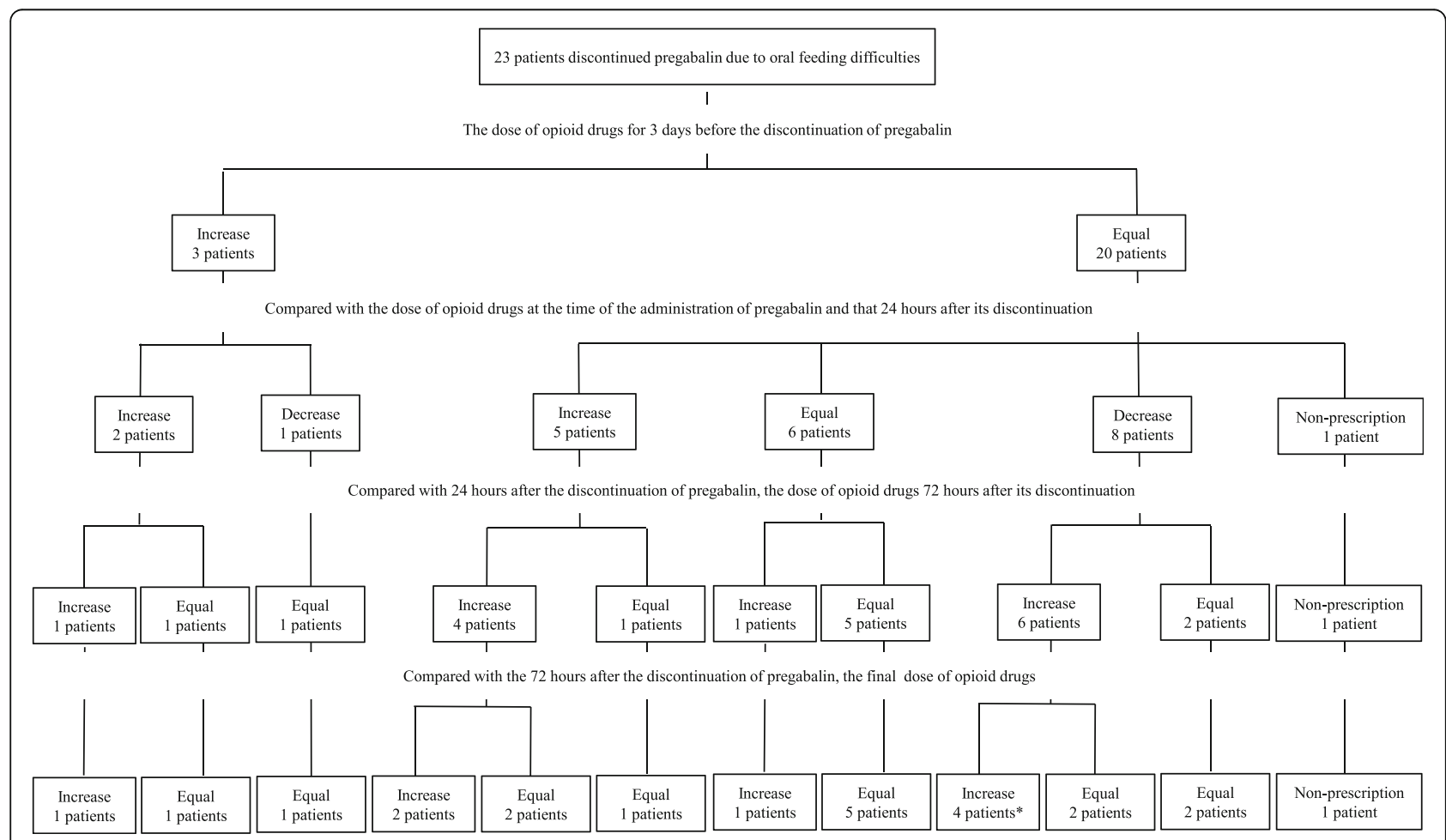

Fig. 1 Changes in the dose of opioid drugs before and after the discontinuation of pregabalin due to oral feeding difficulties. *: Only one example had a lower dose than that before the discontinuation of pregabalin 
Table 5 The final dose of opioid drugs compared with that at the time of the administration of pregabalin

\begin{tabular}{ll}
\hline & Number of patients $(N)$ \\
\hline Increase & 13 \\
Equal & 5 \\
Decrease & 4 \\
Non-prescription (pain control by NSAIDs) & 1 \\
\hline
\end{tabular}

NSAIDs non-steroidal anti-inflammatory drugs

nine patients due to a deterioration in the patient status (including hepatic and renal dysfunctions) (Fig. 1). After the discontinuation of pregabalin, the dose of opioid drugs administered was increased in $56.5 \%$ of patients with oral feeding difficulties (Table 5). For the 7 days before the discontinuation of pregabalin, the dose of pregabalin was increased in one patients and unchanged in 22 patients. Pregabalin is an effective treatment for neuropathic pain that is resistant to opioid drugs. Similar to opioid drugs, pregabalin plays an important role in the control of pain in cancer patients [1]. Isebaba et al. previously performed a questionnaire survey [7]; 52.9-75.2 \% of respondents answered that the use of adjuvant analgesics was effective, while $16 \%$ answered that the dose of opioid drugs administered may be markedly decreased in a large number of patients. Thus, we considered it important to increase the dose of opioid drugs because it is not possible to control pain in patients following the discontinuation of pregabalin.

A new dosage form to continue pain control is needed. Hospital formulations of suppositories have been investigated, and their clinical application is expected [1].

\section{Conclusion}

Regarding the current status of pregabalin treatments in terminally ill cancer patients, all patients discontinued oral pregabalin, and the main reason was oral feeding difficulties. This study clarified that more than $50 \%$ of patients increased the dose of opioid drugs after the discontinuation of pregabalin, with doses being repeatedly increased for some patients. A new route of administration is required for cancer patients who are unable to take oral medication.

\section{Abbreviations}

Ccr: Creatinine clearance; NSAIDs: Non-steroidal anti-inflammatory drugs;

PS: Performance status

\section{Acknowledgements}

Not applicable.

\section{Funding}

Not applicable

\section{Availability of data and materials}

Since this study is a clinical data, it is difficult to cite the information about patients for privacy.

\section{Authors' contributions}

RY, JK, and SK designed the research. KM, YI, NS, YY, and RY performed the experiments and analyzed the data. RY wrote the manuscript. All authors read and approved the final manuscript.

\section{Competing interests}

The authors declare that they have no competing interests.

\section{Consent for publication}

Not applicable.

\section{Ethics approval and consent to participate}

This study was approved by the Ethical Review Board of the Nippon Medical School Hospital (\#28-05-580). This study, an "connection impossible anonymous" didn't need an informed consent.

\section{Author details}

'Section of Pharmaceutical Services, Nippon Medical School Hospital, 1-1-5 Sendagi, Bunkyo-ku, Tokyo 113-8603, Japan. '2Division of Practical Pharmacy, Keio University Faculty of Pharmacy, 1-5-30 Shibakoen, Minato-ku, Tokyo 105-8512, Japan. ${ }^{3}$ Department of Anesthesiology, Nippon Medical School, 1-1-5 Sendagi, Bunkyo-ku, Tokyo 113-8603, Japan. ${ }^{4}$ Department of Palliative Care, Nippon Medical School Hospital, 1-1-5 Sendagi, Bunkyo-ku, Tokyo 113-8603, Japan.

Received: 2 June 2016 Accepted: 27 October 2016

Published online: 05 November 2016

References

1. Arai N, Murata I, Ashigushi A, Nishiyama T, Inoue Y, Kimura M, et al. Characterization of pharmacokinetic parameters for hospital preparation of suppository containing gabapentin tablet. Jpn J Pharm Health Care Sci. 2015;41:861-9.

2. Coyle N, Adelhardt J, Foley KM, Portenoy RK. Character of terminal illness in the advanced cancer patients: pain and other symptoms during the last four weeks of life. J Pain Symptom Manage. 1990;5:83-93.

3. Vadalouca A, Raptis E, Moka E, Zis P, Sykioti P, Siafaka I. Pharmacological treatment of neuropathic cancer pain: a comprehensive review of the current literature. Neuropathic Cancer Pain Pharmacotherapy. 2012;12:219-51.

4. Satija A, Ahmed SM, Gupta R, Ahmed A, Rana SP, Singh SP, et al. Breast Cancer pain management-a review of current \& novel therapies. Indian J Med Res. 2014;139:216-25

5. Matsumoto Y, Shiohama K, Mizogami M, Shigemi K. Risk factors for adverse effects of pregabalin administration. J Jpn Soc Pain Clinicians. 2015;22:123-6.

6. Kato H, Miyazaki M, Takeuchi M, Tsukuura H, Sugishita M, Noda Y, et al. A retrospective study to identify risk factors for somnolence and dizziness in patients treated with pregabalin. J Pharml Health Care Sci. 2015;1:22. doi:10. 1186/s40780-015-0022-7.

7. Isebaba M, Takahashi M, Sadamoto K. The appropritate use of adjuvant analgesics for neuropathic cancer pain. J Jpn Soc Hosp Pharm. 2010;46:1381-5.

Submit your next manuscript to BioMed Central and we will help you at every step:

- We accept pre-submission inquiries

- Our selector tool helps you to find the most relevant journal

- We provide round the clock customer support

- Convenient online submission

- Thorough peer review

- Inclusion in PubMed and all major indexing services

- Maximum visibility for your research 